Article

\title{
One-step post-synthesis treatment for preparing hydrothermally stable hierarchically porous ZSM-5
}

\author{
Jian Ding, Teng Xue, Haihong Wu *, Mingyuan He \\ Shanghai Key Laboratory of Green Chemistry and Chemical Processes, School of Chemistry and Molecular Engineering, East China Normal University, \\ Shanghai 200062, China
}

\section{A R T I C L E I N F O}

\section{Article history:}

Received 31 August 2016

Accepted 30 September 2016

Published 5 January 2017

\section{Keywords:}

\section{Desilication}

Phosphorus stabilization

One-step modification

Hydrothermal stability

Hydrocarbon cracking

\begin{abstract}
A B S T R A C T
Hierarchically porous $\mathrm{ZSM}-5\left(\mathrm{SiO}_{2} / \mathrm{Al}_{2} \mathrm{O}_{3} \approx 120\right)$ containing phosphorus was prepared by a one-step post-synthesis treatment involving controlled desilication and phosphorous modification. The hierarchically porous ZSM-5 featured high thermal and hydrothermal stability. The obtained ZSM-5 zeolites were systematically characterized by X-ray diffraction, scanning electron microscopy, transmission electron microscopy, $\mathrm{N}_{2}$ adsorption-desorption, $\mathrm{NH}_{3}$ temperature-programmed desorption, and ${ }^{27} \mathrm{Al}$ and ${ }^{31} \mathrm{P}$ magic-angle spinning nuclear magnetic resonance spectroscopy. The prepared ZSM-5 displayed enhanced activity and prolonged lifetime toward hydrocarbon cracking. The high activity was attributed to improved coke tolerance owing to the presence of the highly stable mesoporous network of ZSM-5 and acid sites introduced upon phosphorus modification. Additionally a mechanism of the stabilization of the zeolites by phosphorus was proposed and discussed.
\end{abstract}

(C) 2016, Dalian Institute of Chemical Physics, Chinese Academy of Sciences. Published by Elsevier B.V. All rights reserved.

\section{Introduction}

ZSM-5, a typical zeolite with the topological structure of MFI, plays an important role in catalysis [1]. Owing to its high catalytic activity and unique shape-selectivity, it has been widely studied and used in many industrial processes such as alkylation, disproportionation, isomerization, and cracking [2-5]. However, the relatively small pore size $(<2 \mathrm{~nm})$ of conventional ZSM-5 zeolites causes mass-transfer issues, thereby limiting the broad applications of ZSM-5 [6-9]. To overcome this drawback, hierarchically porous ZSM-5, possessing at least two levels of porosity (typically micropores and mesopores), has been extensively investigated. The combined microporosity and mesoporosity can alleviate diffusion limitation issues, thereby improving accessibility to acidic sites of large mole- cules. These advantages can lead to reduced catalyst deactivation and enhanced activity during specific catalysis processes [6-9]. Various strategies for preparing hierarchically porous ZSM-5 have been described in the literature over the past few decades [10-14]. Among them, desilication is a promising approach owing to its low cost, high efficiency $[15,16]$, and convenient operation $[17,18]$.

Additionally, the stability of the mesoporous network plays an important role in the activity and lifetime of a catalyst in practical applications. When the catalyst is exposed to a thermal and/or hydrothermal environment, dealumination typically occurs, leading to collapse of the mesoporous structure and depletion of acidic sites. Thus, it is necessary to stabilize the zeolite structure and acid sites in hierarchically porous zeolites. Phosphorus modification has been proven to be an

\footnotetext{
* Corresponding author. Tel/Fax: +86-21-62238510; E-mail: hhwu@chem.ecnu.edu.cn

This work was supported by the National Natural Science Foundation of China (21403070, 21573073), National Key Technology Research and Development Program (2012BAE05B02), and Shanghai Leading Academic Discipline Project (B409).

DOI: 10.1016/S1872-2067(16)62549-4 | http://www.sciencedirect.com/science/journal/18722067 | Chin. J. Catal., Vol. 38, No. 1, January 2017
} 
efficient method for structure stabilization [19-21]. The framework aluminum pairs can be stabilized by extra-framework cationic species formed by protonation of orthophosphoric acid [22]. As a result, dealumination is inhibited and lattice aluminum is less susceptible to leaving the zeolite framework upon interaction between the framework aluminum and phosphorus [23,24]. These modifications and resulting stabilization are typically conducted on the microporous zeolites. However, mesopores formed by silicon extraction are always disordered and less stable than the microporous structure [25]. Thus, it is important to stabilize the mesoporous network in hierarchically structured zeolites. Although stabilization by phosphorus is demonstrated to be a promising technique to enhance the hydrothermal stability of zeolites, reduction in acid strength occurs inevitably [26-28]. Upon interaction with the zeolitic framework, phosphorus species can substitute the protons on the oxygen of the bridging hydroxyl groups in the zeolitic framework to form $\mathrm{P}-\mathrm{OH}$ by replacing $\mathrm{Al}-\mathrm{OH}$ [29]; such a mechanism maintains the level of acidity of the resulting framework. Accordingly, achieving a balance between stabilization and weakening of acid sites upon phosphorus modification is important to design highly efficient catalysts.

In our previous work [30], hierarchically porous high-silica ZSM-5 with high hydrothermal stability was prepared by desilication and subsequent inorganic phosphorus modification. The obtained hierarchically porous ZSM-5 displayed excellent performance in various acid-catalyzed reactions. However, the synthesis procedure was complex and tedious as it involves multiple steps. Therefore, synthesizing hierarchically porous ZSM-5 with high hydrothermal stability using a more direct and convenient approach is of great interest. Moreover, the stabilization modification was limited to the following phosphorus species: $\mathrm{H}_{3} \mathrm{PO}_{4}$, sodium phosphates, and ammonium phosphates. These phosphorus species would non-selectively distribute in the zeolite channels [31-33]. To more effectively use the phosphorus species, understanding the insertion of phosphorus into the zeolitic framework is important.

Herein, organic quaternary phosphonium hydroxide (TEPOH) was chosen as a novel phosphorus source to enhance the accessibility and interaction with aluminum in the zeolite framework and to avoid leaching of phosphorus from the zeolite channels. Hierarchically porous ZSM-5 zeolites containing phosphorus were prepared using a newly developed method. Subsequently, the catalytic performance of the prepared hierarchically porous ZSM-5 toward dealkylation of 1,3,5-triisopropylbenzene (TIPB) and cracking of 1-octene was examined.

\section{Experimental}

\subsection{Chemicals}

The properties of chemicals used in this work are as follows: $\mathrm{Al}_{2}\left(\mathrm{SO}_{4}\right)_{3} \cdot 18 \mathrm{H}_{2} \mathrm{O}$ (AR, SCRC), $\mathrm{H}_{2} \mathrm{SO}_{4}(98 \%$, SCRC), water glass $\left(\mathrm{SiO}_{2}, 27.1\right.$ wt\%), TEABr (99\%, Sigma-Aldrich), TPAOH (1 mol/L in water, Sigma-Aldrich), NaOH (AR, SCRC), TEPBr (99\%, Alfa Aesar), $\mathrm{Ag}_{2} \mathrm{O}$ (AR, SCRC), TEAOH ( $25 \mathrm{wt} \%$ in water, SCRC), and $\left(\mathrm{NH}_{4}\right)_{2} \mathrm{HPO}_{4}(\mathrm{AR}, \mathrm{SCRC})$.

\subsection{Synthesis of parent ZSM-5 (Z5)}

Parent ZSM-5 (denoted as Z5) was synthesized according to a literature procedure [30]. Briefly, $\mathrm{Al}_{2}\left(\mathrm{SO}_{4}\right)_{3} \cdot 18 \mathrm{H}_{2} \mathrm{O}$ was used as the aluminum source and dissolved in sulfuric acid solution ( $0.65 \mathrm{~mol} / \mathrm{L})$. Then, the solution was mixed with water glass, tetraethylammonium bromide (TEABr), and seeding gel to obtain a mixture with a molar composition of $230 \mathrm{SiO}_{2}: 1 \mathrm{Al}_{2} \mathrm{O}_{3}$ : $11.5 \mathrm{Na}_{2} \mathrm{O}: 11.5 \mathrm{TEABr}: 6900 \mathrm{H}_{2} \mathrm{O}$. The seeding get, containing 0.5 wt $\% \mathrm{SiO}_{2}$, was prepared with a molar composition of $\mathrm{SiO}_{2}: 0.35$ tetraethylammonium hydroxide (TPAOH): $19.6 \mathrm{H}_{2} \mathrm{O}$ at $80{ }^{\circ} \mathrm{C}$ for $3 \mathrm{~d}$. The mixture was hydrothermally treated at $175^{\circ} \mathrm{C}$ for $3 \mathrm{~d}$ to induce crystallization. Then, the as-prepared powder was recovered by filtration, washed with deionized water several times until the $\mathrm{pH}$ of the liquor was neutral, and dried at $100{ }^{\circ} \mathrm{C}$ overnight. The resulting zeolite $\mathrm{Z} 5$ was obtained after calcination at $550{ }^{\circ} \mathrm{C}$ in atmospheric pressure and ion-exchanged to obtain the $\mathrm{H}$-form of the zeolite.

\subsection{One-step post-synthesis treatment of Z5 for preparing Z5-AT@TEP+-a}

To prepare the hierarchically porous ZSM-5 containing phosphorus, Z5 was subjected to a one-step treatment at $70{ }^{\circ} \mathrm{C}$ in an aqueous alkaline solution containing $0.2 \mathrm{~mol} / \mathrm{L}$ of $\mathrm{OH}^{-}$-based solution. Typically, $1 \mathrm{~g}$ of $\mathrm{Z} 5$ was uniformly dispersed into a pre-heated alkaline solution containing $\mathrm{NaOH}$, TEPOH (prepared by TEPBr and $\mathrm{Ag}_{2} \mathrm{O}$ ), and TEAOH with a concentration molar ratio of $\left(\mathrm{TEP}^{+}+\mathrm{TEA}^{+}\right) / \mathrm{OH}^{-}$of 0.2 [34]. The amount of TEP+ ${ }^{+}$was pre-calculated based on the expected $\mathrm{P}_{2} \mathrm{O}_{5}$ loading of $1.5 \mathrm{wt} \%$ on the zeolite. After stirring for $30 \mathrm{~min}$, the mixture was quickly cooled to room temperature and washed until the $\mathrm{pH}$ of the supernatant was neutral. After drying overnight at $100{ }^{\circ} \mathrm{C}$, the hierarchically porous ZSM-5 containing phosphorus was obtained and denoted as Z5-AT@TEP+-a, where AT@TEP+ refers to the concurrent alkaline treatment (AT) and phosphorus (TEP+) modification applied.

\subsection{Preparation of reference samples Z5-AT, Z5-AT@PO $4^{3-}-a$, and Z5-AT-PO4 ${ }^{3-}-a$}

For comparison, three reference samples, i.e., Z5-AT (obtained upon alkaline treatment only, i.e., without phosphorus modification), Z5-AT@PO ${ }_{4}^{3-}$-a (obtained upon alkaline treatment in an inorganic phosphorus-containing solution with concurrent inorganic $\left(\mathrm{NH}_{4}\right)_{2} \mathrm{HPO}_{4}$ modification), and Z5-AT$\mathrm{PO}_{4}{ }^{3-}$-a (obtained upon alkaline treatment, followed by inorganic $\left(\mathrm{NH}_{4}\right)_{2} \mathrm{HPO}_{4}$ impregnation), were prepared as follows.

Alkali treatment of Z5 was performed in an aqueous solution of $0.2 \mathrm{~mol} / \mathrm{L} \mathrm{OH}^{-}$-based solution at $70{ }^{\circ} \mathrm{C}$. Typically, $1 \mathrm{~g}$ of Z5 was uniformly dispersed into a pre-heated alkaline solution containing both $\mathrm{NaOH}$ and TEAOH at a TEAOH-to-OH- concentration molar ratio of 0.2 . After stirring for $30 \mathrm{~min}$, the mixture was cooled rapidly in an ice-water bath. After thorough washing, drying overnight at $100{ }^{\circ} \mathrm{C}$, calcination at $550{ }^{\circ} \mathrm{C}$ for $6 \mathrm{~h}$ in 
atmospheric pressure, and ion-exchange, Z5-AT in H-form was obtained [30].

Z5-AT@PO4${ }^{3--a}$ was prepared by desilication in a pre-heated alkaline solution of $0.2 \mathrm{~mol} / \mathrm{L} \mathrm{OH}^{-}$-based solution, which contained $\mathrm{NaOH}, \mathrm{TEAOH}([\mathrm{TEAOH}] /[\mathrm{NaOH}]=0.25)$ and a known amount of $\left(\mathrm{NH}_{4}\right)_{2} \mathrm{HPO}_{4}$ (based on the expected $\mathrm{P}_{2} \mathrm{O}_{5}$ loading of $1.5 \mathrm{wt} \%$ on the zeolite ). After $30 \mathrm{~min}$ of stirring, the mixture was quickly cooled to room temperature and washed until the $\mathrm{pH}$ of the supernatant was neutral. Z5-AT@PO $4^{3-}$-a was obtained after drying at $120^{\circ} \mathrm{C}$ for $8 \mathrm{~h}$.

Z5-AT- $\mathrm{PO}_{4}{ }^{3-}$-a was prepared by subsequent phosphorus impregnation of Z5-AT. Z5-AT was added to a $\left(\mathrm{NH}_{4}\right)_{2} \mathrm{HPO}_{4}$ solution (the mass percentage of zeolite was $1.5 \%$ calculated by $\mathrm{P}_{2} \mathrm{O}_{5}$ ). The mixture was stirred at room temperature for $4 \mathrm{~h}$ and subsequently heated at $80{ }^{\circ} \mathrm{C}$ under stirring until the mixture turned to a paste. The paste was dried at $120^{\circ} \mathrm{C}$ for $8 \mathrm{~h}$ to remove residual moisture [30].

\subsection{Hydrothermal activation and steam-aging}

Activation of the phosphorus element in the prepared zeolites was performed on an FCC catalyst steam-aging equipment (Beijing Wekindu Technology Co. Ltd.). Specifically, Z5-AT@TEP+-a, Z5-AT@PO $4^{3-}$-a, and Z5-AT-PO $4^{3-}$-a were activated at $550{ }^{\circ} \mathrm{C}$ for $3 \mathrm{~h}$ in $100 \%$ steam ( $\left.4.4 \mathrm{~g} \mathrm{H}_{2} \mathrm{O} / \mathrm{min}\right)$. Following calcination and ion-exchange, the phosphorus-containing samples were obtained in $\mathrm{H}$-form and labeled as Z5-AT@TEP+, Z5-AT@PO $4^{3-}$, and Z5-AT- $\mathrm{PO}_{4}{ }^{3-}$, respectively. The H-type zeolites were also steam-aged at $800{ }^{\circ} \mathrm{C}$ for $17 \mathrm{~h}$ in $100 \%$ steam ( $4.4 \mathrm{~g} \mathrm{H}_{2} \mathrm{O} / \mathrm{min}$ ), and the aged products were denoted with the suffix "-HT".

\subsection{Characterization}

Powder X-ray diffraction (XRD) patterns were collected on a Rigaku Ultima IV powder diffractometer using $\mathrm{Cu} K_{\alpha}$ radiation $(\lambda=0.154184 \mathrm{~nm})$ over a $2 \theta$ range of $5^{\circ}-50^{\circ}$; the accelerating voltage and applied current were $35 \mathrm{kV}$ and $25 \mathrm{~mA}$, respectively. The relative crystallinity of the products was determined from the peak area within a $2 \theta$ range of $22.5^{\circ}-25^{\circ}$ using a commercial ZSM-5 sample, as a reference, supplied by Nankai University Catalyst Co., Ltd. Scanning electron microscopy (SEM) was performed on a HITACHI S-4800 scanning electron microscope, operating at an accelerating voltage of $3 \mathrm{kV}$. High-angle annular dark-field-scanning transmission electron microscopy (HAADF-STEM) images were collected on a JEM-2010, operating at $200 \mathrm{kV}$. The $\mathrm{SiO}_{2} / \mathrm{Al}_{2} \mathrm{O}_{3}$ ratio and $\mathrm{P}$ content in the products were determined by inductively coupled plasma-atomic emission spectroscopy (ICP-AES) on a Thermo IRIS Intrepid II XSP atomic emission spectrometer. $\mathrm{N}_{2}$ adsorption-desorption isotherms were recorded on a Quantachrome Autosorb-3B instrument at $-196^{\circ} \mathrm{C}$. The mesopore size distribution was determined from the adsorption branch of the isotherms using the Barrett-Joyner-Halenda (BJH) model. ${ }^{27} \mathrm{Al}$ solid-state magic-angle spinning nuclear magnetic resonance (MAS NMR) spectra were recorded on a VARIAN VNMRS-400WB spectrometer. ${ }^{31} \mathrm{P}$ NMR measurements were performed with a 4.0-mm MAS probe on a Bruker Avance III spectrometer. $\mathrm{NH}_{3}$ temperature-programmed desorption (NH3-TPD) was conducted on a Tianjin XQ TP5080 automatic adsorption apparatus fitted with a thermal conductivity detector. For the measurements, $100 \mathrm{mg}$ of the H-type samples was pretreated at $550{ }^{\circ} \mathrm{C}$ for $2 \mathrm{~h}$ under helium flow, and $\mathrm{NH}_{3}$ adsorption was conducted at $100{ }^{\circ} \mathrm{C}$. After removing the physically adsorbed $\mathrm{NH}_{3}$, the samples were heated to $550{ }^{\circ} \mathrm{C}$ at a rate of $10^{\circ} \mathrm{C} / \mathrm{min}$.

\subsection{Catalytic tests}

The cracking of 1-octene was performed at atmospheric pressure in a microreactor fitted with a quartz tube with an inner diameter of $8 \mathrm{~mm}$. Before the reaction, $50 \mathrm{mg}$ of 20-60 mesh mixture pellets of zeolite and silica gel (Qingdao), prepared by mass-equal grinding, was packed in a fixed-bed reactor and heated at $650{ }^{\circ} \mathrm{C}$ for $1 \mathrm{~h}$ in a stream of $\mathrm{N}_{2}$. Then, 1-octene was fed with $\mathrm{N}_{2}$ at a constant temperature of $650{ }^{\circ} \mathrm{C}$. The weight hourly space velocity of 1 -octene was $121 \mathrm{~h}^{-1}$. The products were analyzed by two on-line gas chromatograph instruments, GC-9890A (Shanghai Linghua, HP-5 capillary column, $60 \mathrm{~m} \times 0.32 \mathrm{~mm} \times 0.25 \mu \mathrm{m}$ ) and GC-14B (Shimadzu, DM-plot alumina capillary column, $50 \mathrm{~m} \times 0.25 \mathrm{~mm} \times 10 \mu \mathrm{m})$, both equipped with a flame ionization detector. Thermogravimetric (TG) analysis of the spent catalysts was performed on NETZSCH/STA 449 F3; the measurements were conducted in flowing air at a heating rate of $10{ }^{\circ} \mathrm{C} / \mathrm{min}$.

The dealkylation of TIPB was evaluated in a microreactor fitted with a quartz tube of an inner diameter of $6 \mathrm{~mm}$. Prior to the catalytic reaction, $50 \mathrm{mg}$ of 20-60 mesh zeolite ZSM-5 pellets prepared without a binder was pre-treated at $380^{\circ} \mathrm{C}$ for 60 min in a stream of $\mathrm{N}_{2}$. Then, while maintaining a constant temperature of $380{ }^{\circ} \mathrm{C}, 0.5 \mu \mathrm{L}$ of substrate was injected into the catalyst bed with $\mathrm{N}_{2}$ fed from the top of the reactor. The flow of the carrier gas was $80 \mathrm{~mL} / \mathrm{min}$. The TIPB cracking products were analyzed by an on-line gas chromatograph instrument (GC-9800A, Shanghai Kechuang; FFAP capillary column, $30 \mathrm{~m} \times$ $0.25 \mathrm{~mm} \times 0.25 \mu \mathrm{m}$ ), equipped with a flame ionization detector.

\section{Results and discussion}

\subsection{Zeolitic properties}

XRD analysis was performed to investigate possible structural changes in ZSM-5 that occurred upon alkaline treatment and phosphorus modification. The alkaline-treated samples and the organic and inorganic phosphorus-modified samples displayed diffraction patterns similar to that of the untreated zeolite (Z5) (Fig. 1). The intensity of the peaks of all post-synthesis-treated samples decreased slightly. This decrease could be attributed to the removal of $\mathrm{Si}$ from the framework [17]. Though the different post-synthesis treatments led to different degrees of structural collapse, the long-range ordering of the microporous network of all the samples were maintained. Furthermore, the relative crystallinity of all samples was higher than $80 \%$. This result indicates 


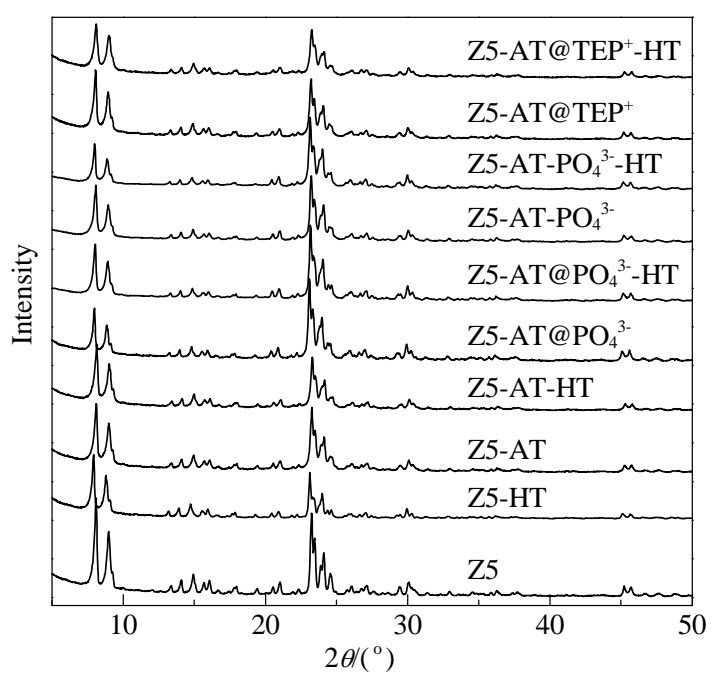

Fig. 1. XRD patterns of the different ZSM-5 samples prepared using different treatments.

that the framework silicon was removed in a controlled fashion with the aid of $\mathrm{TEA}^{+}$cations [35].

Fig. 2 presents the $\mathrm{N}_{2}$ adsorption-desorption isotherms and pore size distributions of the different ZSM-5 samples prepared in the present study. Parent Z5 displayed a typical Type I isotherm, which is characteristic of a microporous system. In contrast, Z5-AT and Z5-AT@TEP+ exhibited Type IV isotherms, characterized by a high $\mathrm{N}_{2}$ uptake at high $p / p_{0}$ values. This fea-

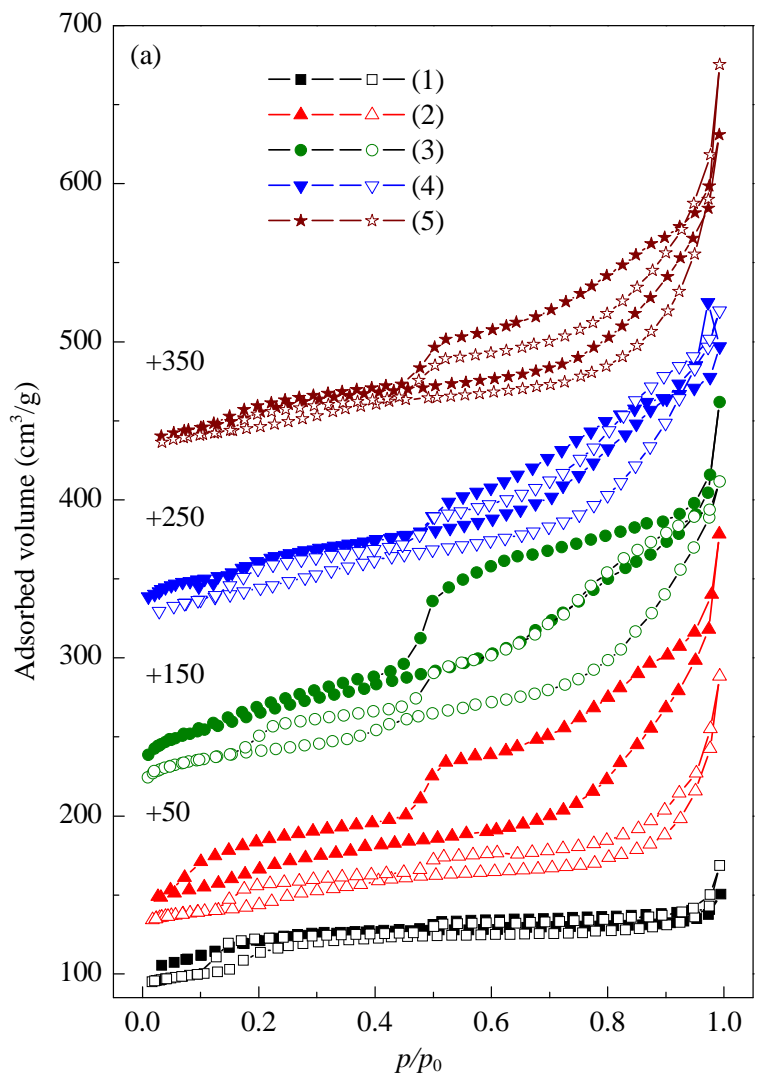

ture indicated that mesoporosity was efficiently introduced in the zeolite framework during desilication. Table 1 presents the physicochemical properties of all the samples prepared. The external surface area $\left(S_{\text {ext }}\right)$ and mesopore volume $\left(V_{\text {meso }}\right)$ of Z5-AT increased considerably from $35 \mathrm{~m}^{2} / \mathrm{g}$ and $0.07 \mathrm{~cm}^{3} / \mathrm{g}$ (Z5) to $159 \mathrm{~m}^{2} / \mathrm{g}$ and $0.37 \mathrm{~cm}^{3} / \mathrm{g}$, respectively. When compared with the $S_{\text {ext }}$ and $V_{\text {meso }}$ of Z5-AT, those of Z5-AT@TEP+ increased to $166 \mathrm{~m}^{2} / \mathrm{g}$ and $0.37 \mathrm{~cm}^{3} / \mathrm{g}$, respectively. Z5-AT@PO ${ }_{4}^{3-}$ and Z5-AT-PO ${ }_{4}^{3-}$ displayed similar isotherms and textural properties.

Additionally, Z5-AT, Z5-AT@PO $4^{3-}$, and Z5-AT-PO $4^{3-}$ featured comparable pore size distribution profiles. This result indicates that the free inorganic phosphate or organic quaternary phosphonium species in solution had minimal influence on desilication. However, the physicochemical properties of Z5-AT following steam-aging changed considerably, indicating an obvious collapse in the framework, as listed in Table 1. Specifically, $S_{\text {ext }}$ of Z5-AT-HT decreased to $74 \mathrm{~m}^{2} / \mathrm{g}$ (from $159 \mathrm{~m}^{2} / \mathrm{g}$ for Z5-AT); however, the Type IV isotherm features were preserved. In contrast, the phosphorus-modified hierarchically porous ZSM- 5 could maintained their textural properties even under severe steam-aging. The level of preservation of the $S_{\text {ext }}$ value (calculated by the ratio of $S_{\text {ext }}$ before steam-aging to $S_{\text {ext }}$ after steam-aging, presented in parentheses below) decreased in the order of Z5-AT@TEP+-HT (86\%) > Z5-AT-PO ${ }^{3-}{ }^{3-H T}$ (79\%) > Z5-AT@PO $4^{3-}$-HT $(51 \%)>$ Z5-AT-HT (46\%), relative to the $S_{\text {ext }}$ before steam-aging. The phosphorus-containing zeolite sample, Z5-AT@TEP+-HT, displayed a lower degree in re-

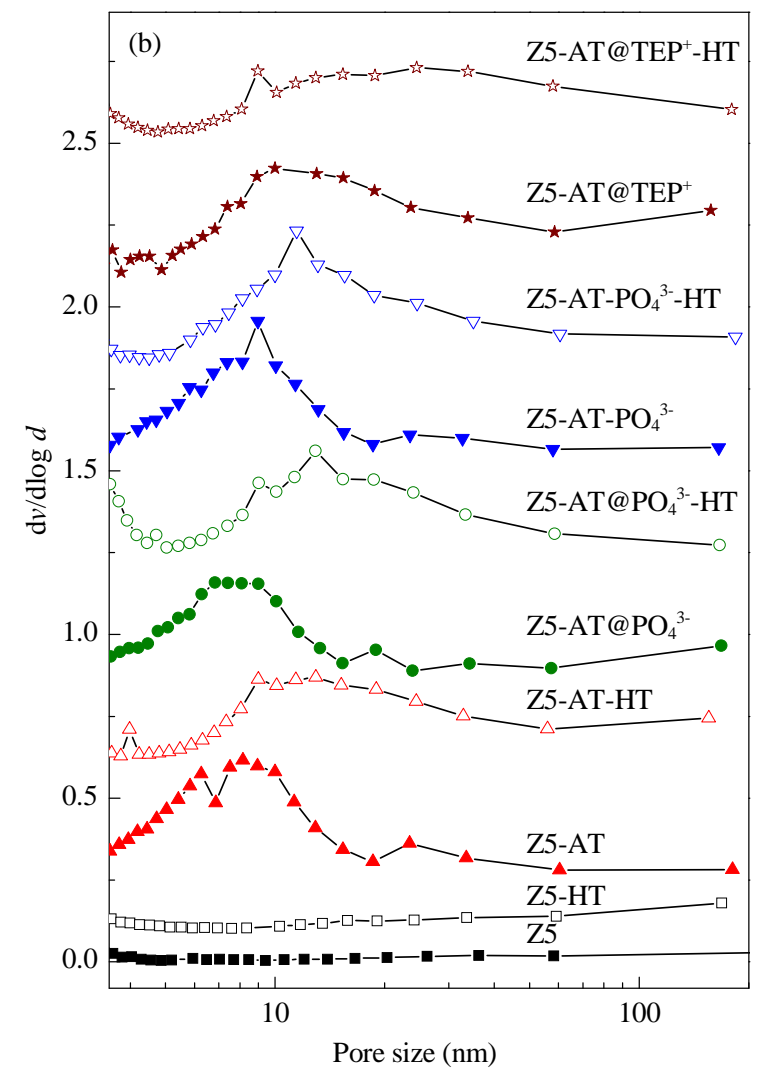

Fig. 2. $\mathrm{N}_{2}$ adsorption-desorption isotherms (a) and pore size (b) of Z5 (1), Z5-AT (2), Z5-AT@ $@ \mathrm{PO}_{4}^{3-}$ (3), Z5-AT-PO4${ }^{3-}$ (4), and Z5-AT@TEP+ (5). The closed markers represent the as-prepared samples and the opened markers represent the steam-aged samples. 
Table 1

Physicochemical properties of the different zeolite samples prepared using different treatments.

\begin{tabular}{|c|c|c|c|c|c|c|c|c|}
\hline Sample & $\mathrm{SiO}_{2} / \mathrm{Al}_{2} \mathrm{O}_{3}$ & P content ${ }^{a}(\%)$ & $\begin{array}{l}\text { R.C. b } \\
(\%)\end{array}$ & $\begin{array}{c}A_{\mathrm{BET}}{ }^{\mathrm{c}} \\
\left(\mathrm{m}^{2} / \mathrm{g}\right)\end{array}$ & $\begin{array}{c}A_{\mathrm{ext}}{ }^{\mathrm{d}} \\
\left(\mathrm{m}^{2} / \mathrm{g}\right) \\
\end{array}$ & $\begin{array}{c}V_{\text {micro }}{ }^{\mathrm{d}} \\
\left(\mathrm{cm}^{3} / \mathrm{g}\right)\end{array}$ & $\begin{array}{c}V_{\text {meso }} \\
\left(\mathrm{cm}^{3} / \mathrm{g}\right)\end{array}$ & $\begin{array}{l}\mathrm{NH}_{3} \text { capacity } \\
\left(\mathrm{mmol}_{\mathrm{NH} 3} / \mathrm{g}\right)\end{array}$ \\
\hline $\mathrm{Z5}$ & 145 & $-\mathrm{e}$ & 100 & 378 & 35 & 0.14 & 0.07 & 0.254 \\
\hline Z5-HT & 152 & - & 93 & 362 & 45 & 0.13 & 0.11 & 0.031 \\
\hline Z5-AT & 105 & - & 92 & 464 & 159 & 0.12 & 0.37 & 0.277 \\
\hline Z5-AT-HT & 111 & - & 81 & 326 & 74 & 0.10 & 0.24 & 0.044 \\
\hline Z5-AT@PO4${ }^{3-}$ & 95 & - & 90 & 470 & 173 & 0.12 & 0.38 & 0.291 \\
\hline Z5-AT@PO ${ }_{4}^{3--H T}$ & 102 & - & 79 & 339 & 88 & 0.10 & 0.30 & 0.054 \\
\hline $\mathrm{Z} 5-\mathrm{AT}-\mathrm{PO}_{4}{ }^{3-}$ & 109 & 1.40 & 93 & 437 & 189 & 0.12 & 0.31 & 0.192 \\
\hline Z5-AT-PO ${ }_{4}^{3--H T}$ & 113 & 1.34 & 95 & 448 & 150 & 0.11 & 0.39 & 0.068 \\
\hline Z5-AT@TEP+ & 115 & 1.44 & 91 & 430 & 153 & 0.12 & 0.35 & 0.215 \\
\hline Z5-AT@TEP+-HT & 110 & 1.46 & 89 & 396 & 131 & 0.11 & 0.37 & 0.107 \\
\hline
\end{tabular}

${ }^{\mathrm{a}}$ Calculated based on the expected $\mathrm{P}_{2} \mathrm{O}_{5}$ loading in the zeolite. ${ }^{\mathrm{b}}$ Calculated within a $2 \theta$ range of $23^{\circ}-25^{\circ}$.

${ }^{\mathrm{c} C}$ Calculated by the Brunauer-Emmett-Teller (BET) method. ${ }^{\mathrm{d}}$ Calculated by the $t$-plot method. ${ }^{\mathrm{e}}$ Undetected.

duction in $S_{\text {ext }}$ than the phosphorus-free zeolite Z5-AT-HT. Similarly, the level of retention of $V_{\text {meso }}$ decreased in following order: Z5-AT-PO $4^{3-}-\mathrm{HT}$ (126\%) > Z5-AT@TEP+-HT (106\%) > Z5-AT@PO $4^{3--H T}$ (79\%) > Z5-AT-HT (65\%). This trend demonstrates that the phosphorus-modified samples possess higher hydrothermal stability than the phosphorus-free sample. The textural properties of Z5-AT@TEP+-HT, especially the mesoporosity, were better preserved than those of Z5-AT-PO $4^{3--H T}$. Thus, higher hydrothermal stability of the mesoporous network was achieved in Z5-AT@TEP+-HT than in Z5-AT-PO $4^{3-}$-HT. Furthermore, the degree of complexity of the one-step post-synthesis treatment employed is lower when compared with that of previous report [11]. Notably, similar textural properties of both Z5-AT@PO $4^{3-}$-HT and Z5-AT-HT were obtained following steam-aging. As observed in Table 1, no phosphorus species was detected in Z5-AT@PO $4^{3-}$. This result indicates that almost no inorganic phosphorus species remains after desilication and related subsequent treatments. Thus, the stabilizing effect provided by phosphorus modification was minimal in Z5-AT@PO4 $4^{3-}$-HT.

SEM images of the samples subjected to different treatment are presented in Fig. 3. The parent Z5 consisted of uniform crystals of $\sim 2 \mu \mathrm{m}$, possessing a typical coffin-like morphology (Fig. 3(a)). No obvious changes in the morphology were ob- served after the various post-synthesis treatments, indicating that desilication occurred in a controlled fashion in the presence of organic cations [34]. Fig. 3(f) shows a HAADF-STEM image of Z5; the bright area highlights a crystalline particle, featuring microporosity only. The presence of extensive intracrystalline mesoporosity formed in Z5-AT@TEP+ zeolite could readily be distinguished by the dark spots against the original bright area, outlining the crystalline particle, in Fig. $3(\mathrm{~g})$. The presence of the newly created mesopores in Z5-AT@TEP+ observed by HAADF-STEM was consistent with the $\mathrm{N}_{2}$ adsorption-desorption results. The results of the mesopore size and $V_{\text {meso }}$ (developed upon treatment in a mixed solution of $\mathrm{NaOH}, \mathrm{TEAOH}$, and TEPOH) of Z5-AT@TEP+ were considerably different from those of Z5 (Fig. 2 and Table 1).

$\mathrm{NH}_{3}$-TPD measurements were conducted to determine the strength and amount of acid sites on the zeolite samples. As observed from Table 1 and Fig. 4, the $\mathrm{NH}_{3}$ capacity on Z5-AT and Z5-AT@ $@ \mathrm{PO}_{4}{ }^{3-}$ was slightly larger than that of the parent Z5 because of the lower $\mathrm{SiO}_{2} / \mathrm{Al}_{2} \mathrm{O}_{3}$ ratio after desilication [36]. The $\mathrm{NH}_{3}$-TPD profile of Z5-AT@TEP+ indicated that the introduction of phosphorus species into the zeolite, especially those adsorbed on strong acid sites, reduced the $\mathrm{NH}_{3}$ capacity. This result confirmed the acid-weakening effect of phosphorus on the zeolite [24]. A similar phenomenon was observed for

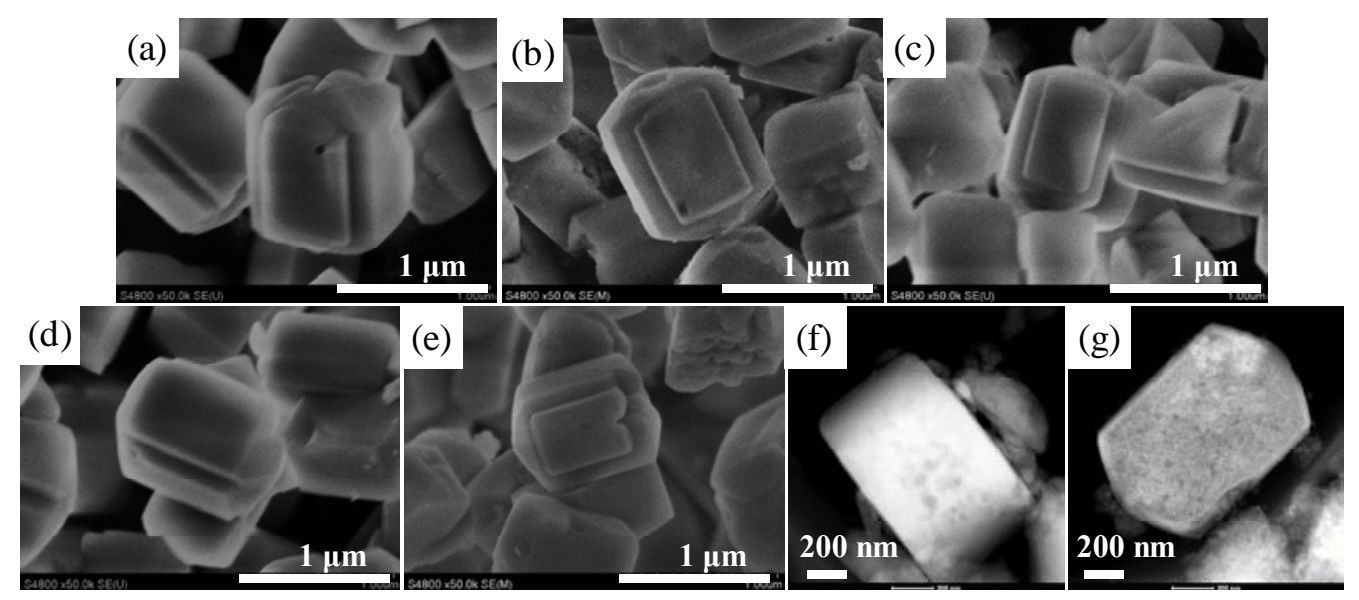

Fig. 3. SEM images of Z5 (a), Z5-AT (b), Z5-AT@PO $4^{3-}$ (c), Z5-AT-PO $4^{3-}$ (d), and Z5-AT@TEP+ (e); HAADF-STEM images of Z5 (f) and Z5-AT@TEP+ (g). 


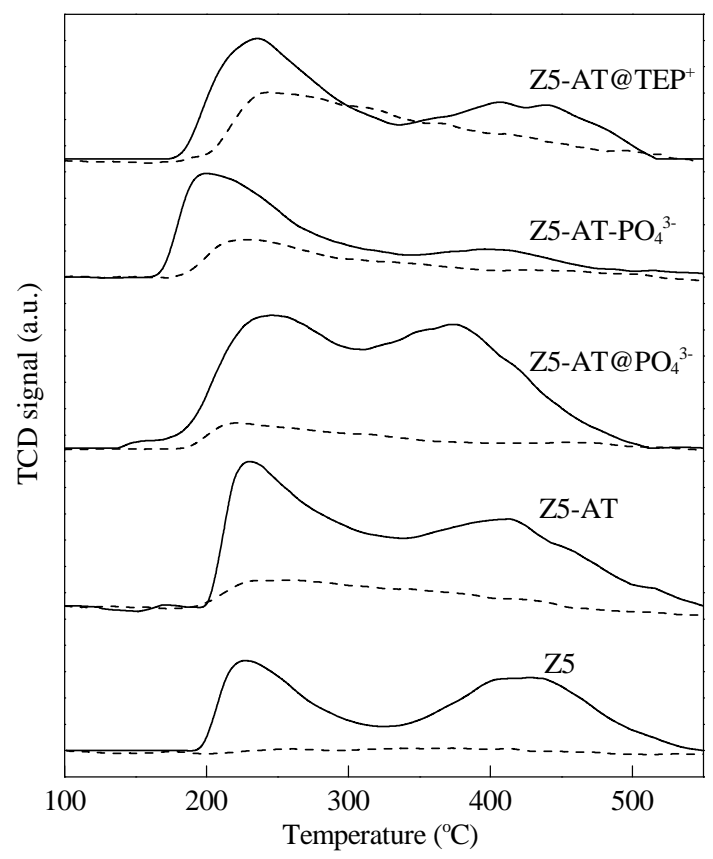

Fig. 4. $\mathrm{NH}_{3}$-TPD profiles of the ZSM-5 zeolites prepared using different treatments. The solid lines refer to the as-prepared samples and the dotted lines refer to the steam-aged samples.

Z5-AT- $\mathrm{PO}_{4}{ }^{3-}$, as consistent with the results in the literature [30]. The total adsorption capacity of $\mathrm{NH}_{3}$ for all samples decreased significantly after steam-aging at $800{ }^{\circ} \mathrm{C}$ for $17 \mathrm{~h}$. This phenomenon was attributed to the occurrence of dealumina-

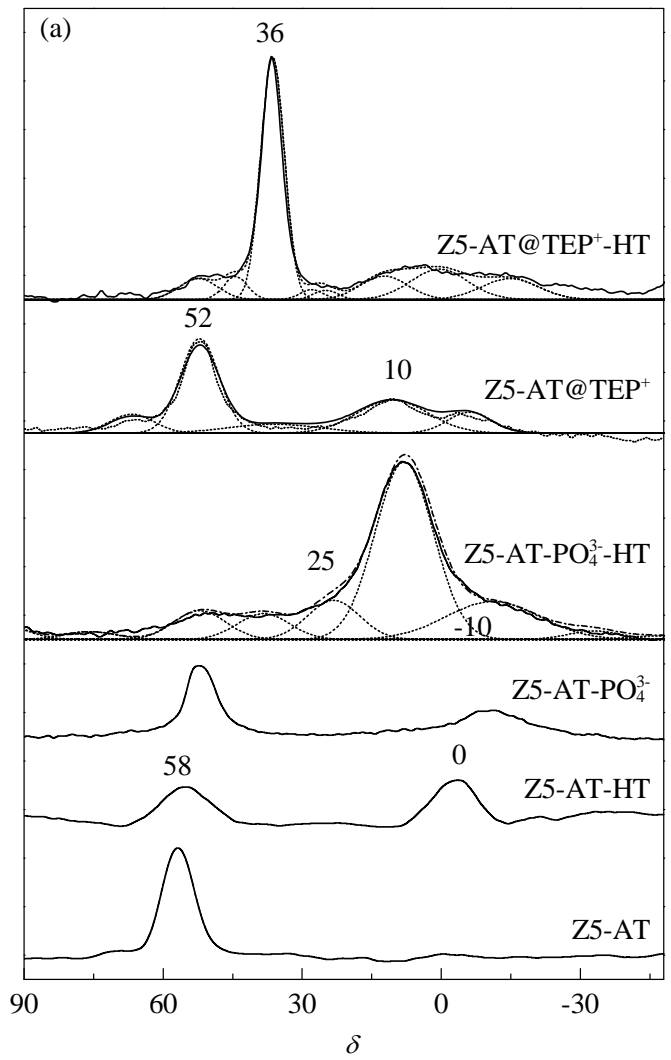

tion and related reduction in acid site density on these samples. The level of retention of acid site density of the steamed samples decreased in the order of Z5-AT@TEP+-HT (50\%) > Z5-AT-PO ${ }^{3-}{ }^{3-H T}$ (35\%) > Z5-AT@PO $4^{3-}$-HT (18\%) > Z5-AT-HT $(16 \%)>$ Z5-HT $(12 \%)$. The acid site density in the phosphorus-containing samples, especially Z5-AT@TEP+-HT, after steam-aging was better preserved than in the phosphorus-free samples [22]. It could be concluded that the acid sites were stabilized because dealumination of the zeolitic framework was inhibited by phosphorus modification [24]. The higher level of preservation of acid site density in Z5-AT@TEP+-HT when compared with that of Z5-AT-PO4 ${ }^{3-}$-HT suggests the efficacy of this simple post-synthesis treatment.

The ${ }^{27} \mathrm{Al}$ and ${ }^{31} \mathrm{P}$ MAS NMR analysis results presented in Fig. 5 provide information on the coordination state of aluminum and phosphorus in the samples prepared using different treatments. In the ${ }^{27} \mathrm{Al}$ MAS NMR spectra of ZSM-5, several peaks, corresponding to different species, were observed at the following positions: $\sim 55 \mathrm{ppm}$ (tetrahedral aluminum in the zeolite framework), $\sim 0 \mathrm{ppm}$ (typical octahedral aluminum in extra-framework positions), $\sim 36 \mathrm{ppm}$ (intermediate aluminum species, tetrahedral aluminum in a distorted environment probably in the zeolite framework or $(\mathrm{SiO})_{x} \mathrm{Al}(\mathrm{OP})_{4-x}$ sites formed by substitution of some silicon with phosphorus atoms at high temperatures), $\sim 10 \mathrm{ppm}$ (octahedral aluminum in a distorted environment attached to phosphate) and $\sim-10 \mathrm{ppm}$ (octahedral aluminum attached to phosphorous) [20,31,37-41]. Only one intense and sharp signal at $57 \mathrm{ppm}$ was observed in the spectrum of Z5-AT, indicating that all the

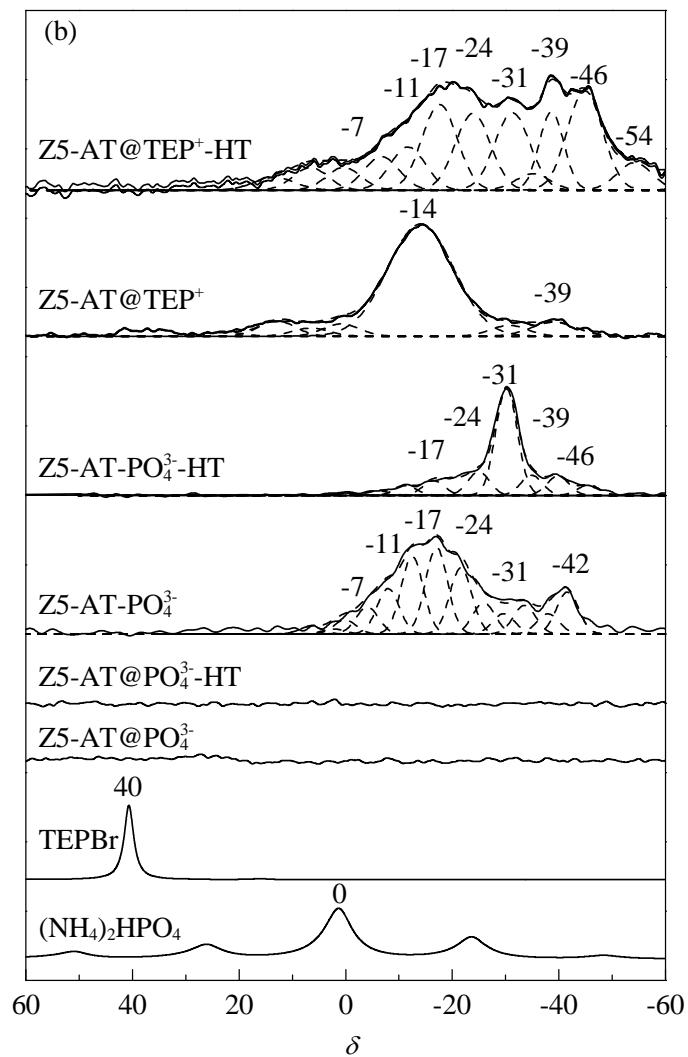

Fig. 5. ${ }^{27} \mathrm{Al}(\mathrm{a})$ and ${ }^{31} \mathrm{P}(\mathrm{b}) \mathrm{MAS}$ NMR spectra of the ZSM-5 samples prepared using different treatments. 
aluminum atoms were tetrahedrally coordinated. Z5-AT-HT contains approximately half extra-framework aluminum (resonance signal observed at $0 \mathrm{ppm}$ ) owing to the occurrence of dealumination during steam-aging. Similar spectra were obtained for Z5-AT@PO ${ }_{4}^{3-}$ before and after steam-aging. In the phosphorus-containing samples, most aluminum maintained their tetrahedral coordination in a phosphorus-interacted environment (resonances at $52 \mathrm{ppm}$ ). In the spectra of Z5-AT-PO $4^{3-}$ and Z5-AT@TEP+, minor signals were observed at $-10 \mathrm{ppm}$, indicating the interaction between newly formed octahedral coordinated aluminum and phosphate during hydrothermal activation. After severe steam-aging, an intense signal at $36 \mathrm{ppm}$ was observed in the spectrum of Z5-AT@TEP+-HT. In contrast, the spectrum of Z5-AT-PO ${ }_{4}^{3-}{ }^{3-H T}$ displayed a weak signal at 30-58 ppm and an intense peak at $10 \mathrm{ppm}$. These results reveal that more framework aluminum have been preserved and stabilized during organic phosphorus modification than during inorganic phosphorus modification. This phenomenon can be ascribed to the fact that $\mathrm{TEP}^{+}$can appropriately ion-exchange with $\mathrm{Na}^{+}$ions, which are mainly located near the aluminum atoms to balance the framework charge. Thus, the propensity of interaction between phosphorus and framework aluminum is enhanced.

31P MAS NMR spectroscopy was used to further investigate the state of phosphorus in the phosphorus-containing samples. As shown in Fig. 5(b), both the spectra of Z5-AT@PO $4^{3-}$ and Z5-AT@PO $4^{3-}$-HT did not feature any signals, attributed to the loss of phosphorus species during preparation of the zeolites. The spectra of the phosphorus-containing samples subjected to hydrothermal activation displayed broad peaks from -7 to -50 ppm and centered at $-14 \mathrm{ppm}$. The signals could be ascribed to either phosphorus in pyrophosphoric acid or terminal groups of polyphosphates not attached to $\mathrm{Al}$ ( -6 to $-8 \mathrm{ppm}$ ), middle and terminal groups of polyphosphates either attached or not attached to $\mathrm{Al}$ ( -12 to $-30 \mathrm{ppm}$ ), and middle groups of highly condensed polyphosphates attached to $\mathrm{Al}$ ( -32 to $-40 \mathrm{ppm})$ [22,31,42-44]. Upon subsequent aging, the coordination of phosphorus changed further. For instance, the spectrum of Z5-AT-PO ${ }_{4}^{3-}$-HT displayed a narrow and sharp signal centered at $-31 \mathrm{ppm}$, which is related to amorphous aluminum phosphate [45]. In contrast, the spectrum of Z5-AT@TEP+-HT displayed a broad and intense resonance from 0 to $-17 \mathrm{ppm}$. This result indicates that the phosphorus species is in a lower state of condensation than that in Z5-AT-PO $4^{3-}$-HT. Condensation is closely related to the dispersion of phosphorus species on zeolites. The lower degree of phosphorus condensation indicates the presence of enhanced interaction between phosphorus and aluminum on Z5-AT@TEP+-HT rather than the occurrence of self-condensation.

Scheme 1 shows a possible stabilization mechanism for hydrothermal activation according to the information gathered on the coordination of $\mathrm{Al}$ and $\mathrm{P}$ species from the ${ }^{27} \mathrm{Al} /{ }^{31} \mathrm{P}$ MAS NMR spectra in Fig. 5 and a previously reported mechanism [30]. During activation, the phosphorus species in TEP+ transform to (poly)phosphates [46]. Most of the framework aluminum retain their tetrahedral coordination state (52 ppm), whereas a few tetrahedral aluminum in Z5-AT@TEP+ are removed from the framework as octahedral aluminum $(0 \mathrm{ppm}$ in the ${ }^{27} \mathrm{Al}$ NMR spectrum of Z5-AT@TEP+), and the octahedral aluminum interact with phosphorus ( $-10 \mathrm{ppm})$. Consequently, in this process, two possible phosphorus-aluminum structures form as presented in Scheme 1 (structures 1 and 2). These structures include both the framework aluminum and extra-framework aluminum attached to the phosphorus. In the subsequent steam-aging process, most of the framework aluminum attach to the phosphorus in a newly distorted environment (36 ppm in the 27Al NMR spectrum of Z5-AT@TEP+-HT). Additionally, a few extra-framework aluminum attach to the phosphorus. Based on this information, we propose that the stabilized structures (structures 3 and 4; broad signal detected ranging from -7 to $-50 \mathrm{ppm}$ in the ${ }^{31} \mathrm{NMR}$ spectrum of Z5-AT@TEP+-HT) are derived upon changes in the structures 1 and 2 during steam-aging.

\subsection{Catalytic activity}

The catalytic activity of all steam-aged samples was evaluated toward cracking of 1-octene. The evolution of the catalytic
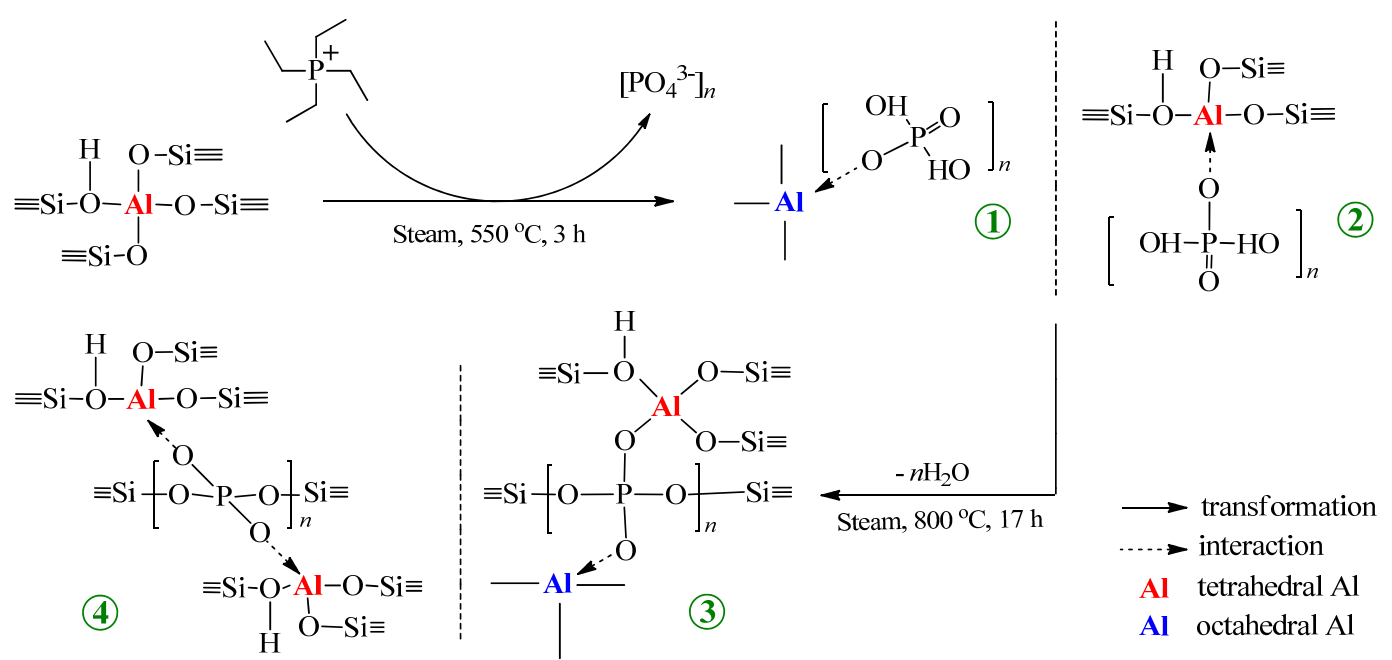

Scheme 1. Proposed mechanism of the interaction between $\mathrm{Al}$ and $\mathrm{P}$ during hydrothermal activation and steam-aging processes. 
activity of the five steam-aged samples as a function of time on stream is shown in Fig. 6(a). High initial conversions (> 95\%) were obtained over all the steam-aged samples. However, the 1-octene conversion over Z5-HT rapidly decreased within 3-15 $\mathrm{h}$ of reaction from $\sim 100 \%$ to $\sim 75 \%$. In contrast, the rate of conversion over Z5-AT-HT reduced at a slower pace; the reduced conversion rate was attributed to enhanced coke toler-
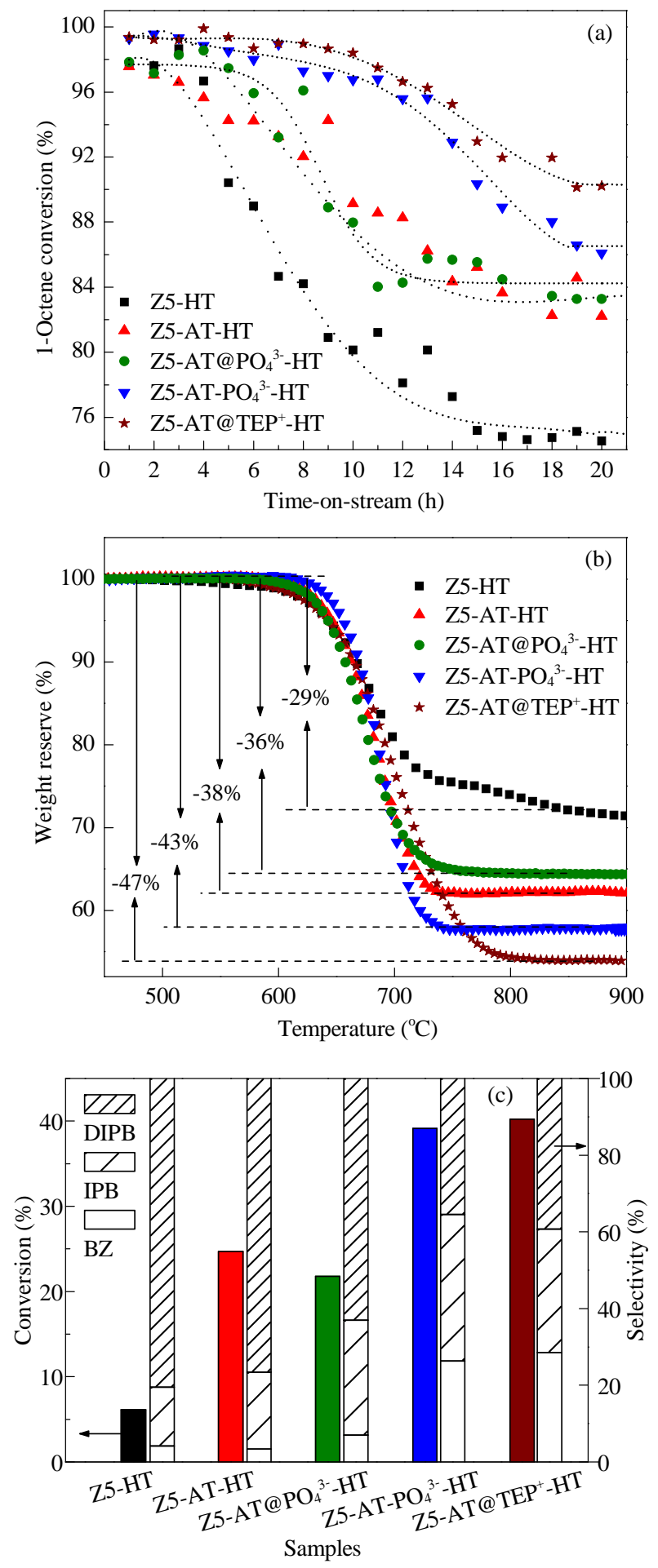

Fig. 6. Conversion profiles (a) and coke content (b) during 1-octene cracking and conversion and selectivity profiles of TIPB cracking over the steam-aged zeolites (c). ance. Z5-AT@PO4${ }^{3--H T}$ displayed a trend similar to that of Z5-AT-HT; the lack of catalytic performance over that sample was attributed to the absence of effective phosphorus modification. The conversion of 1 -octene remained mostly steady (i.e., 98\%) within $10 \mathrm{~h}$ of reaction over Z5-AT@TEP+-HT. A similar trend was observed for Z5-AT-PO $4^{3-}-\mathrm{HT}$, which displayed a conversion of $\sim 97 \%$. When the reaction period was extended further to $20 \mathrm{~h}$, a slight decrease in conversion occurred over Z5-AT-PO ${ }_{4}^{3-}{ }^{-H T}$ (87\%) and Z5-AT@TEP+-HT (91\%). Based on these results, it can be deduced that the presence of hierarchical porosity and stable acid sites in the zeolite catalyst can realize sustainably high conversions of reduced spatial-constrained molecules in an acid-catalyzed reaction.

Coke formation within micropores causes more significant deactivation than that on the external surface owing to pore channel blockage and active site coverage [13]. To further investigate the catalytic performance of the prepared catalyst samples, the coke content on the used samples was analyzed by TG (Fig. 6(b)). The highest coke content was detected on the used Z5-AT@TEP+-HT. This result indicated that the relatively higher mesoporosity and acid density of Z5-AT@TEP+-HT led to higher coke tolerance and longer catalyst lifetime when compared with Z5-HT and Z5-AT-HT $[47,48]$.

The catalytic performance of TIPB cracking is illustrated in Fig. 6(c). TIPB cracking conversion over the differently treated ZSM-5 samples decreased in the order of Z5-AT@TEP+-HT > Z5-AT-PO4 ${ }_{4}^{3-}$-HT > Z5-AT-HT > Z5-AT@PO4 ${ }_{4}^{3-}-\mathrm{HT}>$ Z5-HT. This trend demonstrated that diffusion of TIPB was accelerated by mesopore introduction. Furthermore, higher product selectivity of terminal cracking products benzene (BZ) was observed over Z5-AT@TEP+-HT, indicating that the stabilized acid sites favored the typical acid-catalyzed reactions [49]. Furthermore, the catalytic testing results reveal that hierarchical ZSM-5 containing phosphorus performs better than the parent ZSM- 5 and hierarchically porous phosphorus-free ZSM-5. Additionally, comparison of the zeolites stabilized by phosphorus reveals that the zeolite prepared via a one-step method shows superior catalytic performance than phosphorus-modified zeolites prepared by conventional methods.

\section{Conclusions}

A convenient, one-step post-synthesis treatment to introduce mesopores and phosphorus moieties in high-silica ZSM-5 was successfully developed by controlled desilication under the protection of $\mathrm{TEA}^{+}$. Phosphorus was integrated near framework aluminum in the form of quaternary phosphonium. The characterization studies showed that porosity optimization and structure stabilization were efficiently realized by the one-step method. Consequently, Z5-AT@TEP+ displayed superior catalytic performance than traditionally post-synthesis-treated hierarchically porous ZSM-5 modified with phosphorus. Higher conversions in TIPB dealkylation and remarkably prolonged catalytic performance of Z5-AT@TEP+-HT in 1-octene cracking were realized. Such excellent performance was ascribed to both the optimized porosity and the reduced propensity of structure collapse and acid sites poisoning. 


\section{References}

[1] W. W. Kaeding, L. B. Young, C. C. Chu, J. Catal., 1984, 89, 267-273.

[2] C. Feng, K. Khulbe, T. Matsuura, R. Farnood, A. Ismail, J. Membr. Sci. Res., 2015, 1, 49-72.

[3] B. M. Weckhuysen, J. Yu, Chem. Soc. Rev., 2015, 44, 7022-7024.

[4] D. Kubička, O. Kikhtyanin, Catal. Today, 2015, 243, 10-22.

[5] W. W. Kaeding, C. Chu, L. B. Young, S. A. Butter, J. Catal., 1981, 69, 392-398.

[6] A. Corma, Chem. Rev., 1997, 97, 2373-2420.

[7] J. Pérez-Ramırez, F. Kapteijn, J. C. Groen, A. Doménech, G. Mul, J. A. Moulijn, J. Catal., 2003, 214, 33-45.

[8] M. Hartmann, Angew. Chem. Int. Ed., 2004, 43, 5880-5882.

[9] T. Tago, H. Konno, Y. Nakasaka, T. Masuda, Catal. Surv. Asia, 2012, $16,148-163$.

[10] J. Perez-Ramirez, C. H. Christensen, K. Egeblad, C. H. Christensen, J. C. Groen, Chem. Soc. Rev., 2008, 37, 2530-2542.

[11] J. Ding, J. B. Hu, T Xue, Y. M. Wang, H. H. Wu, P. Wu, M. Y. He, RSC Adv., 2016, 6, 38671-38679.

[12] H. Mochizuki, T. Yokoi, H. Imai, S. Namba, J. N. Kondo, T. Tatsumi, Appl. Catal. A, 2012, 449, 188-197.

[13] M. Choi, K. Na, J. Kim, Y. Sakamoto, O. Terasaki, R. Ryoo, Nature, 2009, 461, 246-249.

[14] B. K. Singh, D. D. Xu, L. Han, J. Ding, Y. M. Wang, S. Che, Chem. Mater., 2014, 26, 7183-7188.

[15] F. L. Bleken, K. Barbera, F. Bonino, U. Olsbye, K. P. Lillerud, S. Bordiga, P. Beato, T. V. W. Janssens, S. Svelle, J. Catal., 2013, 307, 62-73.

[16] J. Li, X. Y. Li, G. Q. Zhou, W. Wang, C. W. Wang, S. Komarneni, Y. J. Wang, Appl. Catal. A, 2014, 470, 115-122.

[17] J. C. Groen, J. A. Moulijn, J. Pérez-Ramírez, J. Mater. Chem. A, 2006, $16,2121-2131$

[18] S. Mitchell, M. Milina, R. Verel, M. Hernández-Rodríguez, A. B. Pinar, L. B. McCusker, J. Pérez-Ramírez, Chem. Eur. J., 2015, 21, 14156-14164.

[19] H. E. Van Der Bij, F. Meirer, S. Kalirai, J. Wang, B. M. Weckhuysen, Chem. Eur. J., 2014, 20, 16922-16932.
[20] M. Derewinski, P. Sarv, X. Sun, S. Müller, A. C. van Veen, J. A. Lercher, J. Phys. Chem. B, 2014, 118, 6122-6131.

[21] Q. Fu, C. P. Kelkar, G. Smith, B. Yilmaz, US Patent 8940652, 2015.

[22] T. Blasco, A. Corma, J. Martínez-Triguero, J. Catal., 2006, 237, 267-277.

[23] T. F. Degnan, G. K. Chitnis, P. H. Schipper, Microporous Mesoporous Mater., 2000, 35, 245-252.

[24] N. H. Xue, X. K. Chen, L. Nie, X. F. Guo, W. P. Ding, Y. Chen, M. Gu, Z. K. Xie, J. Catal., 2007, 248, 20-28.

[25] R. Chal, C. Gérardin, M. Bulut, S. Van Donk, ChemCatChem, 2011, 3, 67-81.

[26] K. Y. Lee, H. K. Lee, S. K. Ihm, Top. Catal, 2010, 53, 247-253.

[27] H. G. Jang, H. K. Min, S. B. Hong, G. Seo, J. Catal., 2013, 299, 240-248.

[28] J. J. Huangfu, D. S. Mao, X. L. Zhai, Q. S. Guo, Appl. Catal. A, 2016, 520, 99-104.

[29] J. A. Lercher, G. Rumplmayr, Appl. Catal., 1986, 25, 215-222.

[30] J. Ding, M. Wang, L. M. Peng, N. H. Xue, Y. M. Wang, M. Y. He, Appl. Catal. A, 2015, 503, 147-155.

[31] G. Caeiro, P. Magnoux, J. M. Lopes, F. R. Ribeiro, S. M. C. Menezes, A. F. Costa, H. S. Cerqueira, Appl. Catal. A, 2006, 314, 160-171.

[32] D. Minoux, C. Adam, N. Nesterenko, S. Van Donk, J. P. Dath, W. Vermeiren, US Patent 9249066, 2016.

[33] D. H. Choo, H. C. Kim, S. J. Kim, J. M. Kim, T. J. Kim, S. Choi, S. H. Oh, Y. S. Kim, D. S. Park, Y. K. Park, C. W. Lee, H. Y. Kim, W. C. Choi, N. Y. Kang, B. S. Song, US Patent 9056308, 2015.

[34] K. Sadowska, K. Góra-Marek, M. Drozdek, P. Kuśtrowski, J. Datka, J. Martinez Triguero, F. Rey, Microporous Mesoporous Mater., 2013, 168, 195-205.

[35] J. C. Groen, L. A. A. Peffer, J. A. Moulijn, J. Pérez-Ramírez, Chem. Eur. J., 2005, 11, 4983-4994.

[36] J. C. Groen, J. C. Jansen, J. A. Moulijn, J. Pérez-Ramírez, J. Phys. Chem. $B, \mathbf{2 0 0 4}, 108,13062-13065$.

[37] Z. M. Yan, D. Ma, J. Q. Zhuang, X. C. Liu, X. M. Liu, X. W. Han, X. H. Bao, F. X. Chang, L. M. Xu, Z. Liu, J. Mol. Catal. A, 2003, 194, 153-167.

[38] Y. Y. Shu, D. Ma, X. C. Liu, X. W. Han, Y. D. Xu, X. H. Bao, J. Phys.

\section{Graphical Abstract}

Chin. J. Catal., 2017, 38: 48-57 doi: 10.1016/S1872-2067(16)62549-4

One-step post-synthesis treatment for preparing hydrothermally stable hierarchically porous ZSM-5

Jian Ding, Teng Xue, Haihong Wu*, Mingyuan He

East China Normal University
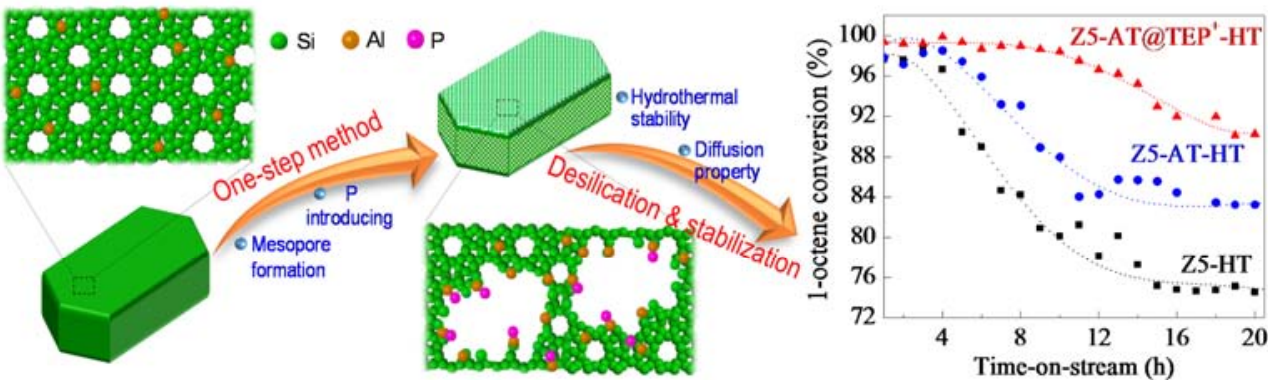

Hierarchically porous ZSM-5 with high hydrothermal stability was obtained by a one-step post-synthesis treatment involving simultaneous controlled desilication and phosphorous modification. The prepared catalyst displayed prolonged catalytic activity and stability toward hydrocarbon cracking. 
Chem. B, 2000, 104, 8245-8249.

[39] C. A. Fyfe, Solid State NMR for Chemists, CFC Press, Guelph, Ont., 1983.

[40] R. F. Nogueira, M. I. B. Tavares, R. A. San Gil, A. G. Ferreira, Mater. Sci. Appl., 2011, 2, 453.

[41] Z. Li, J. Martínez-Triguero, J. Yu, A. Corma, J. Catal., 2015, 329, 379-388.

[42] J. Caro, M. Bülow, M. Derewinski, J. Haber, M. Hunger, J. Kärger, H. Pfeifer, W. Storek, B. Zibrowius, J. Catal., 1990, 124, 367-375.

[43] N. H. Xue, R. Olindo, J. A. Lercher, J. Phys. Chem. C, 2010, 114, 15763-15770.

[44] K. Damodaran, J. W. Wiench, S. M. Cabral de Menezes, Y. M. Lam, J.
Trébosc, J. P. Amoureux, M. Pruski, Microporous Mesoporous Mater., 2006, 95, 296-305.

[45] P. M. Bautista, J. M. Campelo, A. Garcia, D. Luna, J. M. Marinas, A. A. Romero, Appl. Catal. A, 1993, 96, 175-199.

[46] T. Sonoda, T. Maruo, Y. Yamasaki, N. Tsunoji, Y. Takamitsu, M. Sadakane, T. Sano, J. Mater. Chem. A, 2015, 3, 857-865.

[47] Y. Nakasaka, J. i. Nishimura, T. Tago, T. Masuda, Chem. Eng. J., 2015, 278, 159-165.

[48] R. Javaid, K. Urata, S. Furukawa, T. Komatsu, Appl. Catal. A, 2015, 491, 100-105.

[49] S. Al-Khattaf, J. A. Atias, K. Jarosch, H. de Lasa, Chem. Eng. Sci., 2002, 57, 4909-4920.

\title{
一步处理法制备高水热稳定多级孔 ZSM-5 分子篮
}

\author{
丁 键, 薛 腾, 吴海虹, 何鸣元 \\ 华东师范大学化学与分子工程学院上海市绿色化学与化工过程绿色化重点实验室, 上海 200062
}

\begin{abstract}
摘要: ZSM-5 具有较高的催化活性和独特的择形选择性, 因而被广泛用于精细化工和石油炼制等工业过程. 但其较小的孔 道尺寸导致其在反应中尤其在催化过程中的传质受到影响, 从而严重影响催化剂寿命. 为了解决反应过程中分子篮中底 物及产物的扩散限制问题, 近年来关于介微孔复合多级孔道分子篮的研究在分子篮合成领域引起了广泛兴趣, 并取得一定 进展. 但直接合成法存在成本及复杂性问题, 因此在量产的分子篮上进行后改性引入介孔表现出明显优势. 在这一大类处 理过程中, 碱处理造介孔因成本低以及可操作性较高而备受青睐. 但由于脱硅所形成的介孔往往无序, 稳定性较差, 因此 提高其水热稳定性具有重要意义.
\end{abstract}

文献已有较多报道通过磷元素修饰抑制分子篎在水热环境中脱铝, 从而提高分子筛骨架稳定性. 但传统的磷元素修饰 一般采用后续浸渍法, 过程繁琐. 本课题组开发了一步法后处理制备高水热稳定多级孔 ZSM-5 分子篮, 将脱硅过程与磷引 入过程相结合, 以四乙基氢氧化磷(TEPOH)为磷源, 直接处理微孔分子篮得到含磷的多级孔分子篮. 相比于传统的分子篮 磷修饰过程, 该磷物种在处理中优先交换分子篮骨架上铝原子附近用来平衡电荷的钠离子, 从而增加了磷物种与铝物种相 互作用的可能性, 提高了稳化骨架的效果. 基于此, 本文利用氮吸附-脱附、元素分析、X 射线粉末衍射 (XRD)、扫描电镜 (SEM)、透射电镜 (TEM)、氨程序升温脱附 ( $\left.\mathrm{NH}_{3}-\mathrm{TPD}\right)$ 以及 ${ }^{27} \mathrm{Al}$ 和 ${ }^{31} \mathrm{P}$ 固体核磁 (NMR) 等一系列表征技术, 证明该一步后 处理法对分子篮催化性能的作用.

SEM 和 XRD 结果表明, 分子篎在进行各种处理前后, 相对结晶度和分子篮形貌变化不大, 说明大部分微孔得到保留. TEM 测试表明, 经过该一步后处理法得到的分子篮实现了介孔的引入, 介孔孔径在 10-20 nm. 元素分析结果表明, 几乎所 有的磷源物质在该过程中被引入到分子篮上, 实现了介孔和磷物种的同时引入. $\mathrm{NH}_{3}$ - TPD 测试表明, 含磷分子篎在老化前 后较无磷分子篎具有更高的酸性位密度保留度, 说明磷元素对分子篮上的酸性位起到了稳化作用. 孔结构特性数据不仅 说明了脱硅过程中成功引入介孔, 而且含磷分子篮老化前后的介孔特性数据保留度明显高于无磷样品, 实现了磷元素对介 孔结构的稳化作用. ${ }^{27} \mathrm{Al}$ 和 ${ }^{31} \mathrm{P}$ NMR 结果从理论上证明了该样品上磷元素对抑制骨架脱铝的稳化效应, 证实了分子篮在 处理后水热稳定性的提高.

基于前期的研究工作, 本文完善了磷元素对分子笁稳化作用的机理过程. TEPBr 在水热活化过程中转变成磷酸盐, 并 修饰分子篮的骨架铝以及部分难以避免的非骨架铝. 该过程中形成的磷铝物种在后续的水热老化过程中进一步修饰分子 篎骨架铝, 使骨架铝得到稳化. 而在脱硅过程中存在的“反插铝”过程往往使大部分骨架铝位于介孔孔道中, 磷元素与铝元 素的相互作用同时也对介孔进行了稳化. 通过正辛烯和 1,3,5-三异丙苯的裂化测试发现, 处理后的分子篮由于其优化后的 孔道性能和酸性性质, 大大提高了底物分子的转化率以及其自身的容碳能力, 从而延长了催化寿命.

关键词: 脱硅; 磷修饰; 一步处理法; 水热稳定性; 烃类裂解

收稿日期: 2016-08-31. 接受日期: 2016-09-30. 出版日期: 2017-01-05.

*通讯联系人. 电话/传真: (021)62238510; 电子信箱: hhwu@chem.ecnu.edu.cn

基金来源：国家自然科学基金 (21403070, 21573073); 国家科技支撑计划 (2012BAE05B02); 上海市教委重点学科建设项目 (B409).

本文的英文电子版由Elsevier出版社在ScienceDirect上出版(http://www.sciencedirect.com/science/journal/18722067). 